\title{
TRADUCCIÓN LITERARIA E INCOMUNICACIÓN HISPÁNICA \\ Sobre la historia, apasionante y problemática, de la versión al español (1943) de una obra de R. L. Stevenson (1850-1894)
}

\author{
A Eulalia Galvarriato, \\ atenta, de siempre, a la vida, \\ maestra en la escritura, \\ sutil, ejemplar en la traslación...
}

José Polo

Universidad Autónoma de Madrid

0. A manera de introducción

«Cosa de bibliotecas», con su trasfondo, podría haber sido, igualmente, un rótulo apropiado para llamar la atención sobre los hechos que irán haciendo acto de presencia a lo largo de estas notas. Pues, en efecto, se trata de esas realidades curiosas - aunque no tanto en nuestro medio- que se nos presentan ante los ojos a las personas que frecuentamos las bibliotecas, que nos movemos entre libros. Son síntomas ya no sabemos de qué, pero siempre con un fondo de lo que cabría denominar «incomunicación» (aquí literaria), ausencia de métodos de exploración adecuados en las editoriales, ligereza ante la afirmación o negación de determinados hechos o, sintetizando, una muestra más del «despiste nacional». Entremos ya en materia. 


\section{Méjico-1917/España-1983}

a) En 1983 publica Ediciones Hiperión (Madrid) Ensayos literarios de Robert Louis STEVENSON (tr. de Beatriz Canals y Juan Ignacio de Laiglesia). En NoTA - sin firma particular, o sea, representativa del pensamiento de la entidad editora - se habla muy oportunamente de la importancia de ese escritor, de los rasgos de su obra, de su situación editorial en lengua española, etc. Entre las páginas 7 y 8 leemos:

[...] Sucede, eso sí, que los editores recuerdan a veces que no es fácil encontrar en las librerías determinadas obras de determinados autores y deciden reeditarlas cuando están agotadas o mandarlas traducir y darlas a conocer cuando no se han publicado antes en su país. Entonces, sencillamente, están cumpliendo una función cultural necesaria, la de facilitar el acceso del público lector a ciertas obras que consideran de interés.

Este ha sido y es el caso de Stevenson. Un par de obras del gran novelista escocés son reeditadas a menudo en colecciones populares y es harto fácil encontrarlas. Mientras tanto, sigue habiendo buen número de páginas suyas de innegable calidad que no han sido aún traducidas a nuestro idioma. Así, estos Ensayos literarios, INÉDITOS EN SU TOTALIDAD EN CASTELLANO [relieve mío] y que Ediciones Hiperión saca hoy a la luz como antes hiciera con sus poemas, nunca traducidos con anterioridad.

b) Pues bien: no es verdad lo de «inéditos en su totalidad». Sin haber realizado investigación especial alguna -de otro modo: habiendo tropezado prácticamente con la realidad que describo-, puedo afirmar que el primero de esos ensayos, el titulado "Carta a un joven que se propone abrazar la carrera del arte», ya estaba, desde hacía muchos años, traducido a nuestra lengua: «Carta a un joven que se propone seguir la carrera artística», último de los escritos incluidos en Ensayos (tr. de Francisco José Castellanos), en Cultura [Méjico], V-6/1917, XI+65 págs. ¿Que cómo se entera una editorial de esas cosas? Muy sencillamente: explorando en las bibliotecas (que para eso están), comenzando, por ejemplo, con la Biblioteca Nacional, en la que resulta muy fácil hallar, bajo /Stevenson, Robert Louis/, y en la sección de obras traducidas, este opúsculo, especie de tirada aparte de revista o número monográfico. La fragilidad de determinadas afirmaciones contundentes sobre si algo está o no está traducido a nuestro idioma, ejemplificando ahora con ensayo de un autor equis, es 
al mismo tiempo sugerencia para que otros hurguen en esta zona de andar sobre el alambre, con la seguridad de que toparán con frutos sazonados. Pero ya es hora de comenzar la historia de nuestra «vieja traducción».

a) En la página de derechos, además de la fecha de $1^{\circ}$ de noviembre de 1917, aparece el dato de que se han tirado 100 ejemplares numerados y que ese hace el número 47 . Donde se halla anunciada, portadilla, «Nota preliminar, aparece, manuscrita, la siguiente dedicatoria del traductor: «Al culto poeta D. Enrique Díez-Canedo, homenaje de admiración de [...]».

b) Reproduzco ahora la instructiva nota de presentación, sin rótulo alguno, firmada por «La Dirección [de Cultura]» (pág. VII):

Ofrecemos hoy a nuestros lectores la traducción que nuestro amigo Francisco José Castellanos ha hecho de algunos de los mejores ensayos de Robert Louis Stevenson.

Este escritor escocés ha sido considerado por el brillante crítico Arthur Symons como uno de los grandes maestros de la moderna prosa inglesa, al lado del refinado y exquisito Walter Pater.

El traductor es un estudioso joven de Cuba, cuyo nombre será mañana, sin duda, uno de los más famosos en las letras antillanas. Cultiva su espíritu con humildad; lee de continuo los mejores libros; y mira la vida sin prejuicios, sin curiosidades frívolas y sólo con un alto sentimiento de contemplador desinteresado.

CULTURA le agradece públicamente -por medio de estas líneas- el que haya suministrado a los lectores de México una concienzuda traducción de algunos ensayos del fuerte y generoso Stevenson.

c) No se aparta de la realidad quien ha hablado, líneas atrás, de la concienzuda labor traductora de Francisco José Castellanos; él mismo es el autor de una breve introducción, págs. IX-XI, a R. L. Stevenson, presentación escrita con altura literaria y que acaba con las siguientes palabras:

Por cuanto valga también para prestarles el único valor de fidelidad que en virtud de una eficaz contribución puedan tener las traducciones que siguen, deseo testimoniar mi gratitud a mis cultos amigos, Adèle y Luis Baralt y Zacharie, quienes me han ayudado a revisar y corregir este trabajo. 
d) Bien: dos cosas, cuando menos, cabría hacer en torno a estos materiales: 1) realizar un estudio comparativo de esas dos traducciones del ensayo sobre los jóvenes y la carrera artística; 2) seguramente valdría la pena reeditar, ahora como libro pleno, esa cuidada traducción de 1917.

II

\section{Virginibus puerisque y otros ensayos: una traducción, al parecer desconocida, de Eulalia Galvarriato}

a) Verá, lector: en una de mis primeras charlas amistosas con la fina escritora Eulalia Galvarriato, hoy viuda de Dámaso Alonso, supe de cómo ella había traducido al español, allá por los años cuarenta, una obra de R. L. Stevenson en cuyo título entraban como palabras iniciales unas latinas: Virginibus puerisque; que no había rastro de esa traducción: ni ella misma poseía ejemplar alguno ni habían podido hallarla en bibliotecas pese a los movimientos realizados por personas relacionadas con el mundo, siempre misterioso, del libro. En fin...

$b$ ) Pues bien: esa traducción existe; pero, contando con fallos normales en la memoria de las personas, con un determinado grado de «imperfección» en algunas bibliotecas, con distracciones de naturaleza varia en el propio investigador de un caso dado, es natural que las cosas se compliquen y se conviertan en algo casi imposible; pues, además y sobre todo, no era esperable hallar tal obra bajo Virginibus puerisque, sencillamente porque la editorial que publicó esa traducción, apartándose del título originario, le puso al volumen el nombre - ¡muy específico, se ve!- de Ensayos, es decir, exactamente igual que el opúsculo de 1917 presentado en I-1.

c) Se trata de Editorial Escelicer (Madrid-Buenos Aires-Cádiz en esa época), 1943: «traducción del inglés por Eulalia Galvarriato de Alonso». La edición es, cuando menos, atípica: no posee página de derechos: no hay, pues, forma de saber con qué editorial de habla inglesa se relacionaron (si tal fue el caso), en qué edición se basaron para la traducción, etc. La fecha que he dado está tomada del colofón, que reza así: 
SE ACABÓ DE IMPRIMIR ESTE LIBRO EL

DIA 24 DE JULIO DE 1943, VISPERA DE

LA FESTIVIDAD DE SANTIAGO APÓSTOL, PATRON DE ESPAÑA, EN LOS TALLERES

DE LA EDITORIAL ESCELICER, S. L., SITOS

EN LA CALLE CANARIAS, 24, MADRID.

LAUS DEO

$+$

d) Todo lo anterior (incluyendo la propia dificultad en hallarla, lo que finalmente he logrado: Biblioteca Nacional, Madrid) podría llevarnos a atar otros muchos cabos y a sacar algunas conclusiones sobre cómo funcionan las cosas de la cultura en nuestro medio. Uno se pregunta: ¿se trató de una edición normal?; ¿qué tirada se hizo?; ¿cómo se explica su ausencia en tantas bibliotecas del país que lo vio nacer traducido? Pero, sobre todo para mi propósito de ahora, surge esta otra: ¿cómo es posible que en 1979 se hiciera en el mundo hispánico otra versión de la obra y no se dijese una sola palabra de la magnífica traducción ya existente desde 1943 ?

a) Porque, en efecto, en 1979, como acabo de decir, publica Taurus Ediciones (Madrid), de nuestro autor, Virginibus puerisque y otros escritos (tr. de Mary Sol de Mora; prólogo de Fernando Savater). Aquí estamos ya frente a una edición normal desde el punto de vista «externo»: hay página de créditos (nos enteramos, pues, del título original: Virginibus Puerisque and other Papers, Charles Scribner's Sons, Nueva York, 1911 [la primera, en Londres, 1881]): todo en regla, salvo el detalle, «interno", de que no hay la menor referencia a la versión previa, la exquisita de Eulalia Galvarriato: ¿no sabían de su existencia (desorientados quizá por el título que Escelicer le había puesto al volumen, Ensayos)?; ¿no exploraron bibliotecariamente «a fondo»?; ¿conocían el hecho o, al menos, sospechaban de él? No vale la pena, en este momento, hacer más preguntas ni contestar a las formuladas porque, sea lo que fuere, no acabamos de salir de uno más de los esperpentos nacionales.

b) Concentrémonos, pues, en la comparación mínima, de urgencia, entre esas dos traducciones. 1) Aparte la diferencia de títulos, indebida la de Escelicer (salvo que se basara en una edición original titulada Essays, cosa 
que ignoro, pero que, así de entrada, me parece improbable [la profesora Ana Pinto me confirma que no existe: véase más adelante 3]), hay, digo, otro hecho digno de ser notado: el último escrito del volumen de 1943, «Yoshida-Torajiro», no figura en el de 1979 [ni en ediciones en inglés, según me indica la investigadora líneas atrás mencionada]; por el contrario, «Algunos retratos de Raeburn», de esta segunda versión (1979), no se halla en la primera, la de 1943. Sin conocer las varias ediciones en inglés, no es posible saber qué ha ocurrido: si tal diferencia es de origen (distintas ediciones en inglés) o si se debe a cualquier otro motivo [véase, no obstante, más adelante IV].

c) En fin, al igual que apunté en el caso del traductor del opúsculo de 1917, ahora diré que la versión de Eulalia Galvarriato, sin haber realizado estudio comparativo alguno con la de 1979 o cotejo con su original inglés, produce en el lector la sensación de un idioma fluido, muy natural —parecería que está escrito casi directamente en español-, en el que se combina la expresión sencilla, bella en su transparencia, con la solución noblemente literaria, muy cuidada en sus matices, precisa en la delimitación sinonímica, con un sentido rítmico - consecuencia, en cierto modo, de los vaivenes estilísticos de Stevenson- llevado delicadamente a la práctica. En suma: quien tradujo de ese modo fue una persona que puso sus finos saberes idiomáticos de escritora al servicio de una obra a cuya versión se entregó en plenitud. Vocación literaria, dominio del lenguaje y amor hacia la obra objeto de atención laboral, laboriosa, no podían dar sino una traducción de altura, no importa la suerte editorial que tal versión haya tenido. Esperemos, sin embargo, que pronto vea la luz (no sé si «de nuevo» o «prácticarnente por primera vez»): que la vea [ya ha sido: colección El Libro de Bolsillo, Clásicos, número 1379, de Alianza Editorial, Madrid, 1994, al cuidado de quien esto escribe y de Pinto].

\section{Final de esta parte}

Desde un hecho humano elemental -unos minutos de amable diálogo con Eulalia Galvarriato, viuda de Dámaso Alonso- me puse en marcha para intentar rescatar una traducción importante sepultada por las circunstancias, hasta lograr tal resurrección (siempre con ayuda acumulada de unos y otros: véase más adelante IV-8). Han salido al paso diversas realidades complementarias en una accidentada pero, al final, gratificante ruta; y de todo ello hemos aprendido, aunque la sorpresa no sea plena, pues ya sabemos mucho de los há- 
bitos «culturales» de nuestro medio. Quedan varias tareas pendientes: una de ellas, por ejemplo, el estudio comparativo de las dos traducciones mencionadas (habrá, sin duda, colegas interesados en esta clase de investigación). Expuesto algo de «mi aventura» desde el lado hispano y creado ya el contexto mínimo de esta zona, necesitada de exploración más amplia, es la Dra. Pinto quien ha estudiado la vertiente inglesa de la historia que nos ocupa: véase su trabajo «La traducción: lo literal y lo literario. Estudio comparado de dos traducciones al español de una obra de R. L. Stevenson», en Estudios Ingleses de la Universidad Complutense (Madrid), ¿2/1994 (Homenaje a Emilio Lorenzo)?; al parecer, en prensa.

III

\section{Algo sobre el autor}

a) No es nada fácil para un hispanista trazar en pocas líneas el perfil -entre vital, vitalista y finamente literario - de Robert Louis Stevenson, cuyo aniversario de su muerte, 1994, coincide justamente con el año de edición de esta obra en «versión resucitada», recuperada para lectores de varias generaciones del mundo hispanohablante. A través de las palabras enhebradas más adelante, 2, en torno al volumen que nos ocupa, cabrá igualmente captar algunos de los rasgos configuradores de su personalidad, rica en matices, fruto todo ello de una experiencia humana - material e intelectual, afectiva - variada y, al mismo tiempo, intensa en las cosas esenciales, las que afectan lo nuclear del ser humano: la fidelidad a unos principios, la amistad, lo universal desde los particulares hechos de la vida cotidiana, la idea, profundamente vivida, de la esperanza como la última cosa que debemos perder; mejor dicho: como lo que jamás debemos dejar escapar de nuestras manos. En fin, conviene que él nos hable, aunque sea indirectamente, a partir de la obra que el lector podrá disfrutar una vez que ha vuelto al mundo (compárese atrás 3). Pero vienen muy oportunamente a nuestro encuentro unas precisas y expresivas palabras, de principios de siglo, del cubano Francisco José Castellanos, en su traducción de Ensayos, del mismo Stevenson (véase atrás I-1), pág. IX, nota, palabras que muy oportunamente nos sintetizan la trayectoria vital de una personalidad tan compleja como la de nuestro autor:

Robert Louis Stevenson Balfour nació en Edimburgo el 13 de noviembre de 1850 . Desde niño tuvo una salud endeble, y una acen- 
drada y pertinaz afición a las letras. Hizo estudios de ingeniería, que no acabó, y de derecho, que concluyó a los veinticinco años, sin que llegara a ejercer esta profesión. En 1879 hizo un viaje a California para casarse allí al año siguiente. De vuelta a Europa, y cambiando frecuentemente de lugar, en ella estuvo hasta el 87, en que partió de nuevo para Norteamérica. Un año después, emprendió un viaje por el Pacífico, del cual no regresó. Visitó las Marquesas, Tahití, Honolulú, y se fijo poco después en Vailima (Samoa), de donde se ausento por poco tiempo, escasas veces, y en donde murió el 3 de diciembre de 1894. La de Stevenson fue una vida de amplia y profunda influencia personal y actuación humana. Su obra artística es varia y extensa, habiendo escrito considerable número de novelas, cuentos, ensayos, cartas y poesías.

\section{La obra}

a) ¿Qué observa un lector atento en un conjunto de ensayos como el que nos ocupa? En primer lugar, una especie de «equilibrio dialéctico» entre los extremos o vaivenes de nuestro recorrido vital: el éxito y el fracaso, el escritor y el público, la juventud y la vejez, la vocación y la experiencia, lo histórico y lo mitologico, etc. Cabría hablar, sin resquicio de duda, de «su humanismo»: por debajo y por encima de todos esos juegos «contrastivos» en busca de un equilibrio posible, está el sentido humano que impregna a los personajes, a las situaciones que actúan en su obra; el hombre es el punto neurálgico de todas las cosas del mundo, de nuestro mundo. Deberíamos añadir a lo ya expuesto el tono matizado, «íntimo», con que aborda las mil cuestiones que preocupan - pues no han dejado de hacerlo- al hombre de carne y hueso del planeta que habitamos, aunque la ilustración inmediata circule por ámbitos más reducidos (lo universal en lo particular), todo ello con una finura psicologica y sociológica notable y con un amor por el detalle magistralmente realizado desde el ángulo literario. No andaremos alejados tampoco de la realidad afirmando que nuestro autor es algo así como un «deleteitoso degustador o sibarita de los mil vericuetos que la vida nos ofrece o nos impone», amante de la belleza, del placer y, en las duras situaciones vitales, de la esperanza por encima de todo; «equilibrista profesional» entre realismo e idealismo: observador, muy atento, de la cara y la cruz de las cosas que nos circundan; pedagogo, probablemente sin proponérselo, que se nos cuela por entre los huesos porque las lecciones de la vida que nos va presentando nos calan, como la lluvia fina, con su exquisita sensibilidad ( $\tan$ bien recreada en su versión por Eulalia Galvarriato, que, 
uniendo a lo anterior la fidelidad textual, ha convertido el original inglés en algo translúcido, con arreboles de muy particular belleza literaria). Los grandes sentimientos de los seres humanos quedan - tal es la sensación- aparentemente diluidos, «estratégicamente distribuidos», de modo que el lector no se sobresalte y pueda disfrutar auténticamente del placer del texto (no reñido, pues, con «los grandes contenidos»: sin que uno sirva de interferencia con respecto al otro).

b) También podríamos decir de esta obra que representa ella un ejemplo sobresaliente de lo que, desde hace mucho tiempo, conocemos como «comunicación fática»: algo que va mas allá del mero acto de presencia, que conecta a los interlocutores con el hilo del «hablar por hablar», de la conciencia de que coinciden seres virtualmente dialogantes que deben, que conviene pasen al acto mismo interlocutivo, a la proximidad realizada a que nos invita el propio hecho de lo humano; esto es: se trata de personas con virtualidad expresiva, con los mecanismos necesarios para que tal facultad pueda, lejos del absurdo anquilosamiento, mostrarse a si misma como «realmente existente». ¡Qué bien retrata la actuación de los personajes, con qué maestría los representa también en su interior y de qué modo integra todo ello con el entorno, con lo externo o marco de «los sucesos del mundo»! Más adelante, IV (donde aparece lo que podríamos denominar «intrahistoria de la versión al español de esta obra»), se transcriben unas palabras del que seguramente fue el segundo lector oficial del texto en nuestro idioma - se supone que el primero fue el corrector de pruebas (si lo hubo)-, de Leopoldo Panero (allí se explica todo esto), palabras que, de manera muy sencilla, resumen con acierto lo que esta obra representa. A ese hermoso y breve pensamiento hecho verbo remitimos.

c) Poco más conviene añadir, en este contexto, sobre el libro que nos ocupa; no es este el lugar para ir desmenuzando los contenidos de esos «ponderados capítulos", tan ensayísticos, tan sueltos, dentro, claro está, de un aceptable orden. Al menos, llamaremos la atención sobre dos hechos: 1) repasando los títulos de esos ensayos, se ve inmediatamente cómo unos son transparentes del todo (ya se nos anuncia el contenido esencial, sus líneas maestras), otros lo son menos y, finalmente, algunos, los menos, resultan enigmáticos, sugerentes ya desde la magia del propio nombre, por la aureola creada instantáneamente. Sin convertir esta especie de nota de presentación en algo erudito o de recuento de datos, basta con dar tres muestras de tal ruta clasificatoria: «La gruñona vejez y la juventud», por ejemplo, no deja lugar a dudas; no sabemos de antemano qué pasará, valga el caso, en «Algunos retratos de Raeburn» (estoy pensando en el lector promedio, no en un especialista consumado en los temas de que se habla); y, desde luego, no ha lugar para dema- 
siadas concreciones apriorísticas en AEs Triplex (a partir de estos especímenes, establézcanse diversos paralelismos jugando con los ensayos restantes). 2) Lo anterior, sin embargo, no debe tomarse al pie de la letra: Stevenson siempre nos sorprenderá; nunca deja de ofrecer realmente bastante más de lo que uno como lector podría esperar. Su maestría literaria llega, teóricamente al final del camino, a desarrollar con oportunas matizaciones domeñadas, que no pierden al lector, un mundo de ideas y de sentimientos que van más allá de los lugares y tiempos históricos en los que existieron, para quedar, sus reflexiones sobre la vida, su tono —en el fondo, más esperanzador que irónico o escéptico- , su fina lección de nobleza y de calidad y perennidad literarias. No en vano es considerado un clásico, alguien nunca alejado de nuestras vidas lectoras (y algo más). En síntesis: una gran capacidad de observación de la vida, una sobresaliente agudeza para captar los matices del alma humana y una fina escritura son rasgos que se imponen inmediatamente a quien se acerque a esta colección de ensayos, de cuyos datos originarios se da noticia en el artículo de Ana Pinto ya mencionado (II-2).

\section{Recapitulación}

En 1894 moría en Vailima (Samoa) el escritor escocés Robert Louis Stevenson, que había nacido en Edimburgo en 1850 . Inquieto viajero por esos mundos de Dios, vivió intensamente los años de vida que le fueron dados y nos dejó a las generaciones posteriores, cuando menos, incitantes obras de creación literaria. Ahora, 1994, cuando se cumple el centenario de su muerte, aparece la traducción de Eulalia Galvarriato de una de sus obras más sugerentes: Virginibus puerisque... Podrá el lector sumergirse en ella y dejarse llevar plácidamente por la agudeza de observación de las experiencias vitales (y no cualesquiera) y por la lente que las capta con el enfoque preciso para que la imagen resulte atractiva y justa. Los grandes sentimientos humanos (la amistad y el amor, las actitudes hacia el progreso, la sensibilidad frente a los placeres de contemplación de la naturaleza, etc.), filtrados a través de una pluma de fino calibre, nos atrapan enseguida y nos llevan de la mano hacia espacios abiertos unas veces y, otras, hacia los lugares escondidos de nuestro espíritu. El equilibrio de visión y escritura, la maestría en el arte de describir e interpretar: he aquí, entre otros, dos rasgos de su estilo que atraerán irremediablemente al lector de este libro. Pero, si ello no fuera suficiente, no se olvide la calidad literaria puesta al servicio de su versión (rescatada de 1943) por la fina escritora Eulalia Galvarriato. 


\section{ALGO MAS SOBRE LA INTRAHISTORIA DE NUESTRA TRADUCCIÓN (AMPLIACIÓN Y SIINTESIS)}

El volumen que el lector puede ya tener en sus manos (véase atrás II-2-c) fue publicado por Editorial Escelicer (Madrid) en 1943; el colofón, ya se dijo, es del 24 de julio. Pero el libro o no llegó a circular o, al parecer, lo hizo de manera muy limitada (comienzo de mi hipotesis). Ni la propia traductora poseía ejemplar alguno de este conjunto de ensayos. En 1979 -también se ha dicho- una conocida editorial madrileña saca lo que en principio se pensaría es la primera versión al español, ignorando, casi seguro, el hecho de su realísimo nacimiento hispano muchos años antes. Este probable desconocimiento queda explicado al menos, si no justificado, porque la obra de 1943 debió de sufrir algún tipo de percance (inmediato bloqueo o enterramiento en vida, por ejemplo), del que acaba de librarse.

Editorial Escelicer (Establecimientos Cerón [impresor] y Librería Cervantes, S. L.) hizo algo llamativo: no solo titular la obra con el nombre genérico Ensayos y no hacer constar en lugar alguno los datos técnicos de derechos de edición, sino también prescindir del ensayo titulado en el original inglés «Some Portraits by Raeburn» y suplirlo por otro, «Yoshida-Torajiro», que aparece no en el sitio que correspondería al texto suplantado, sino en último lugar ${ }^{1}$. «Yoshida-Torajiro» es, como se ha dicho, un ensayo de Stevenson: tras publicarse previamente en The Cornhill Magazine (XLI/1880, marzo, páginas 327-334), fue recogido en otra colección de ensayos titulada Familiar Studies of Men and Books en 1882; ocupa el quinto lugar en la serie, lugar del que nunca se ha movido en las posteriores ediciones y reimpresiones inglesas del libro ${ }^{2}$.

1 Continúa siendo una incógnita por qué fue «Retratos de Raeburn» el ensayo excluido del texto español. Cabría apuntar algunas posibilidades: parecida extensión (compárese más adelante, nota 5, a efectos de manipulación a partir de este hecho) y el exotismo del nombre en ambos casos (para «despistar») podrian haber facilitado la conmutación de un ensayo por otro.

2 Para estos últimos datos (incluyendo los de la nota anterior), véase el trabajo de ANA PINTO mencionado en II-3. 
¿Por qué Escelicer hace este trueque? Cualquiera que lea «Yoshida-Torajiro», que aparece en la reciente edición española como apéndice, comprenderá inmediatamente, a poco que sepa del contexto político de nuestro país [España] en 1943, que se trata de algo «revolucionario», intolerable para un régimen que no admitía con facilidad esa clase de actos, algo más que simbólicos, de protes$\mathrm{ta}^{3}$. Dicho de otro modo y presentando ya directamente una hipotesis como justificación posible de lo que parece extraña desaparición del libro: probablemente fue secuestrado y, como consecuencia de ello, quedó cortada de raíz su difusión. Da la impresión de que el volumen entero era sólo un pretexto para hacer entrar lo que políticamente interesaba, «Yoshida-Torajiro», colándolo de rondón en una colección de ensayos, inocuos desde la susodicha perspectiva política, que respondía al titulo original inglés Virginibus Puerisque and other Papers. El hecho de que aparezca como parte final de la obra puede no ser casual: en situación problemática por razón de la censura, cabría suprimirlo, dejando el resto tal cual, sin necesidad de reajustar la paginación. En este último supuesto, queda la duda sobre la suerte que pudiera haber corrido «Algunos retratos de Raeburn», el relato desgajado ${ }^{4}$.

${ }^{3}$ Hay una serie de pistas - me comenta Ana Pinto (véase además su artículo, ya mencionado en II-3) - , que podrían explorarse convenientemente fuera del presente trabajo, susceptibles de arrojar alguna luz sobre este embrollado asunto: a) José $\mathrm{M}^{\mathbb{8}}$ Pemán -monárquico liberal, como es bien sabido- fue uno de los socios fundadores de Escelicer y el ensayo "Yoshida-Torajiro» no es ajeno al espíritu de «rebeldra monárquica» cuando menos latente en esos años vivos de la postguerra española; $b$ ) en el entorno «editorial» de la versión de esta obra habia personas ligadas a instituciones escolares muy alejadas de lo impuesto por los gobernantes de aquel entonces; $c$ ) la existencia, según $R$. DE LA CiERva (Época, $n^{2} 44,30$ de agosto de 1993, 67), de papeles de una conspiración de civiles y militares monárquicos contra Franco en 1943, conspiración cuya proclama se escribió en $A B C$ y se tiró en una impresora de la embajada estadounidense.

4 Consultado el expediente de censura de la obra, tenemos, sin embargo, los siguientes (y, solo en parte, sorprendentes) datos: $a$ ) registro general n..$^{8} 15.239$; expediente $n .^{\circ} 2807$; entrada: 24-4-1943; salida: 5-5-1943; $b$ ) entre los datos presentados por Jorge Villén Ecija (secretario personal de J. $M^{*}$ Pemán), en representación de Escelicer, figura el nombre de Dámaso Alonso como traductor de la obra; la tirada, según tal documento, fue, o iba a ser, de 2.500 ejemplares; el número de páginas, 200 , exactamente las que tuvo la edición que vio la luz (si dejamos fuera una más, del índice, al final, y el colofón; $c$ ) informó de esta obra el censor número 1 , que fue - se ve perfectamente la firma - Leopoldo Panero; $d$ ) he aqui la forma como L. Panero rellenó el formulario de la Vicesecretaria de Educación Popular/Delegación Nacional de Propaganda/Censura/Edición: VALOR LITERARIO o ARTISTICO: considerable; VALOR DOCUMEN. TAL: ninguno; MATIZ POLfTICO: ninguno; TACHADURAS (CON REFERENCIA A LAS PÁGINAS): [no aparece nada escrito]; OTRAS OBSERVACIONES: colección de ensayos humorísticos, muy finos, so- 
Sin entrar aquí en más precisiones ${ }^{5}$, conviene señalar que, después del hallazgo por mi parte (1992) de la versión de Escelicer, ha llegado a manos de Eulalia Galvarriato (en 1993) un ejemplar «vivo», en rústica (tal como se publicó), pero con una dedicatoria muy expresiva de una amiga suya (perfectamente identificada, por otra parte, y ya fallecida): «Decís Stevenson y tú: "Dicen que la esperanza no nos abandona nunca"6. Así espero yo también que tampoco abandones jamás este libro; este libro que, adornándome con méritos tuyos, jcon qué orgullo te ofrezco!». La fecha que aparece, debajo del texto y después de Madrid, es 17 de mayo de $1945^{7}$.

bre diversas costumbres inglesas y temas de carácter general, como el matrimonio, la mujer, etc. El estilo es vivaz y lleno de gracia. No hay nada censurable en su contexto. Los datos acabados de presentar son lo suficientemente claros como para que persistan las muchas incógnitas en torno a esta «novelada», ya que no novelesca, versión al español de dicha obra de Stevenson. Cabría añadir que entre 1941 y 1943 se publican en España otros libros de Stevenson $y$, al parecer, sin problema alguno, lo que podía, igualmente, haber ayudado al lanzamiento de este conjunto de ensayos.

${ }^{5}$ A pesar de las muchas pesquisas realizadas en esta dirección, no me ha sido posible localizar el ejemplar - presumiblemente «en capillas » o similar- que Leopoldo Panero tuvo en sus manos a la hora de hacer el reglamentario informe. Ello habría permitido confirmar si en alguna de las primeras páginas del volumen aparecía, en efecto, el nombre de Dámaso Alonso como traductor y si, por consiguiente, tras el visto bueno de la censura, se cambio, previo a la encuademación, por otra página, en la que ya figuraba Eulalia Galvarriato como traductora, que así fue como salió en 1943 (correspondiendo a la verdad, pues ella fue quien tradujo la obra, como sabemos). Otra cosa que habría podido comprobarse es si al final del volumen ya estaba el ensayo «(Yoshida-Torajiro)» o, cambiado de sitio, "Algunos retratos de Raeburn», de una extensión aproximada, con lo que el número de páginas que aparece en el expediente, 200 , se podía haber mantenido jugando con varios recursos tipográficos al alcance de cualquier profesional (en nuestro caso se opero, fundamentalmente, suprimiendo puntos y aparte, juntando texto).

${ }^{6}$ El texto se halla al comienzo de la segunda sección del primer ensayo del volumen (aunque esa idea de no perder nunca la esperanza aparece igualmente en otros lugares). La autora de la dedicatoria ha intercambiado xen ninguna circunstancia de nuestra vida», original de la traducción, por «nunca», perfecto en ese contexto.

${ }^{7}$ Lo del año no es un dato completamente fijado - pues hay duda sobre si el último guarismo es un 3 o un 5 -, pero parece estar más cerca de lo segundo (he preguntado a varias personas, mostrándoles el original, y predomina esa relativa seguridad gráfica). En redacción anterior, cuando aún parecía se tratase de la fecha finalmente desechada, decíamos: «Ya es de por sí enigmática tal dedicatoria (ahora lo es algo menos: la persona que tradujo "Yoshida-Torajiro", que, sin duda, es quien escribió esas bellas palabras a Eulalia Galvarriato, traductora del conjunto del volumen y amiga suya muy querida, se siente honrada con figurar, silenciosamente, anónimamente, al lado del nombre de la traductora "oficial" para que encima hagamos constar que, frente a la mencionada fecha del colofón del libro ( 24 de julio, "víspera de la festividad de 
Todavía hay que dejar constancia de varios hechos. Editorial Escelicer se dirigió a Dámaso Alonso para que vertiese al español esta obra de Stevenson. Dámaso Alonso, imposibilitado de realizar esa tarea por falta material de tiempo y conocedor de las condiciones sobresalientes de Eulalia Galvarriato, su mujer, sugirió el nombre de ella para tal labor, que nuestra escritora llevó a cabo, como se puede cotejar, a conciencia y de manera singularmente pulcra. Otro dato curioso que la traductora recuerda perfectamente es que el ejemplar inglés que la editorial le entregó había pertenecido a la biblioteca de Pedro Salinas (como se sabe, amigo entrañable del matrimonio Dámaso Alonso/Eulalia Galvarriato) ${ }^{8} \mathrm{y}$, aunque tentada a devolvérselo a su dueño afectivamente más cercano, lo hizo, en cambio, a la editorial que se lo había dado. Ella nunca llegó a ver pruebas de imprenta...

¿Quién tradujo "Yoshida-Torajiro»? No parece probable que haya sido Eulalia Galvarriato. Aparte no «sonarle» a ella ese texto como suyo, el cotejo entre el original inglés y la versión española permite afirmar que la calidad de ese último «capítulo» no es la misma que la del resto de los ensayos. Y, aunque no existen seguramente errores básicos, el texto español carece de la claridad y fluidez que Eulalia Galvarriato supo reflejar en los otros ensayos. Todo lleva a suponer que «Yoshida-Torajiro» es traducción de otra persona realizada sin conocimiento por parte de la responsable de la versión del conjunto de la obra, confiando posiblemente, quien moviera todos esos hilos, en que el nombre de Eulalia Galvarriato

Santiago Apostol, patrón de España"), la que aparece tras esas vibrantes palabras sea la de 17 de mayo de 1943. ¿Hubo una "preedición" de nuestro libro? ¿Se trata solo de "lapso cronológico"? ¿Apareció la obra realmente en la primavera de ese año y se puso, por razones de conveniencia (situación nada extraña en el mundo editorial), una fecha "protocolaria", facticia, simbólica, en el colofón?» (EDICIÓN DE MULA: «la que se publica antes de la fecha que aparece en el pie de imprenta o, a falta de éste, en el colofón si existe»: así suelen definir las obras especializadas - pero, según me comunica José Martínez de Sousa, aplicado a los diarios y con la connotación «de origen argentino»— este concepto de edición: anticipada, sea o no prematura o precoz.

8 Véanse, por ejemplo: Dámaso Alonso, «España en las cartas de Pedro Salinas», en Ínsula,VII-74/1952, págs. 1 y 5 (recogido en el vol. Iv, 1975, págs. 205-213, de sus Obras completas, Gredos, Madrid); Eulalia GalvarRiato, «Una amistad: Pedro Salinas y Dámaso Alonsom, en Revista de Occidente [3.' Epoca], 126/1991, págs. 45-54. 
(o, tal vez, el de Dámaso Alonso) protegería la publicación y la difusión de la obra. Ha de darse por prácticamente seguro que E. G. sí tradujo el ensayo ausente en la edición de 1943 (no cabe pensar que lo desgajaran del original): «Algunos retratos de Raebum». Al preguntarle a ella sobre sus recuerdos de esta traducción, dice una y otra vez: «Traduje el ejemplar COMPLETO, que la editorial me ofreció y que era [al menos, había sido: véase atrás 5] propiedad de Pedro Salinas».

Las características de la edición que acaba de publicarse (véase atrás II-2-c) son las siguientes: a) el último ensayo de la edición de 1943, «YoshidaTorajiro», continúa en el mismo lugar, pero ahora aparece, con portadilla y como apéndice, desligado en cierto modo de los ensayos que compusieron tal obra de Stevenson; b) «Algunos retratos de Raeburn» ha sido reinstalado y en su propio lugar'; c) de la preparación del texto para su nueva composición se ha encargado, fundamentalmente, quien esto escribe; en el proceso de corrección de pruebas ha colaborado Ana Pinto; d) se moderniza la acentuación, se salvan las escasas erratas advertidas en la edición de 1943 y se realizan determinados reajustes ortotipográficos para hacer más legible el texto; e) en materia de puntuación y en muy pocas cuestiones más, menores, se han realizado algunos cambios; f) de la preparación de las notas que, concentradas, aparecen al final del volumen, atinentes a referencias de contenido de la obra, se ha encargado Ana Pinto (yo las he revisado desde el punto de vista externo, de presentación tipográfica, etc.).

Es obligado cerrar este trabajo con un capítulo de agradecimiento a las personas que me han ayudado en la laboriosa ruta que me llevo, en primer lu-

${ }^{9}$ No ha sido posible recuperar la traducción de este ensayo realizada en su día por Eulalia Galvarriato. Lo ha hecho para esta edición Ana Pinto, que ha contado con «la inestimable ayuda de Emilio Lorenzo, experto traductor, entre otros dones», en palabras de la propia traductora; en la revisión final ha intervenido igualmente quien esto escribe, junto a la propia A. P., así como un colaborador, anónimo, de Alianza Editorial (con sugerencias muy oportunas): «[...] de los posibles errores de la versión actual es responsable sólo la traductora», nos recuerda dicha investigadora. 
gar, a hallar «el libro perdido y hallado en el templo» - como distendidamente le decía yo a Eulalia Galvarriato cuando hablábamos del asunto- y posteriormente a mover los hilos editoriales para su edición (con el ulterior proceso de preparación del texto): a) en primer lugar, a la traductora «original», acabada de mencionar, por su deliciosa versión, pletórica de aciertos estilísticos, de soluciones exactas y bellas a un mismo tiempo. b) A la profesora Ana Pinto (del Departamento de Filología Inglesa de la Universidad Complutense, Madrid), a quien invité a que estudiara el lado inglés de esta historia y que luego ha compartido conmigo las tareas de edición. c) Al profesor Santiago Mollfulleda (Barcelona) por una gestión bibliotecaria que me permitió enfocar de otro modo la búsqueda que hacía del misterioso volumen y hallarlo posteriormente. d) A la profesora $\mathrm{M}^{\sharp}$ Jesús Fernández Leborans (Madrid), que miró, para mí, dos o tres bibliotecas del ámbito universitario complutense, aunque sin éxito (porque no era posible con los datos que entonces poseía y, sencillamente, porque la obra buscada ni estaba allí ni está en casi ningún lugar). e) A D. Fernando de Toro-Garland, con quien hablé varias veces del entorno de Escelicer, donde él había trabajado, y que hizo más de una pesquisa para ahondar en difíciles pistas. f) A D Concepción Pintado (Archivo General de la Administración Civil del Estado, Alcalá de Henares), que me atendió con amabilidad y eficacia en la búsqueda y consulta que hice del expediente de censura (véase atrás nota 4) de la obra estudiada. g) En fin, doy las gracias a muchas otras personas del mundo bibliotecario madrileño a las que he molestado, a veces telefónicamente, con el sano propósito de remover cielo y tierra para dar con el paradero desconocido de... un libro — sin saberlo el pobre - rico en aventuras.

\author{
V \\ APÉNDICE:
}

Dos anotaciones de Eulalia Galvarriato

$0-1$

En prensa ya este trabajo, he encontrado en casa de nuestra traductora (gracias a la amabilidad de permitirme bucear por carpetas mil) dos notas que tienen relación con lo que he narrado: la primera, muy breve, especie de ficha; la segunda, a manera de diario, nos hace entrar en su mundo de reflexiones en torno a uno de los capítulos de la obra que, presumiblemente entre 1942 y 
1943, tradujo. Esta última nota podía haber ido en la reciente edición del volumen de Stevenson (véase atrás I1-2-c), pero ya es tarde para ello; así que la recupero entre estas páginas, con la idea de que no se pierda tan expresivo texto. Porque, además, se trata de algo escrito a lápiz con letra menuda y más bien difuminada por el paso de los años (casi seguro, fue redactado entre 1942 y 1943).

En mi primer contacto con dicho texto, apenas pude llegar a leer aproximadamente un 50\% (trazos perdidos, etc.). He hablado telefonicamente con D. José Luis Rodríguez Rigual (técnico encargado del vídeo en la Facultad de Filosofía y Letras de la Universidad de Zaragoza) como primera orientación sobre los pasos convenientes para desciframiento o recuperación de ese texto; posteriormente me han ayudado D. Alejandro García Moreno y D." Paloma de Espínola (IBM de la Universidad Autónoma de Madrid), así como D. Javier García Turza (colega mío en 1993), especialista en Paleografía. Todo ello, más las continuas lecturas personales y, a solicitud mía, la de la propia autora del escrito, Eulalia Galvarriato, ha servido para que solo me hayan quedado unas cuantas unidades lingüísticas sin descifrar. No contando de momento con la ayuda técnica (un videomicroscopio), necesaria para superar esas últimas dificultades, prefiero, con la aquiescencia de su dueña, dar el texto al público, pero, eso sí, dejando los huecos correspondientes a los segmentos - casi siempre, meras palabras - no entendidos. Lo prefiero a sugerir posibles «interpretaciones» de escasa seguridad y, por lo tanto, poco instructivas en tal situación. Paso, pues, a transcribir esos dos textos: el sencillo, y aproblemático gráficamente, y el más extenso y, a la vez, resistente aún a su completa intelección. Las interpolaciones mías van entre corchetes.

[Tras fichar la obra de Stevenson Virginibus puerisque, que es como nuestra traductora la recordaba - no como Ensayos, título con el que apareció en 1943_, anota:] No tengo ni un solo ejemplar y no recuerdo la fecha [1943, como sabemos]; debió ser por el final de los 40 o principios de los cincuenta. Creo que el editor fue Escelicer [en efecto]. 
Explico todo esto por si alguien localiza algún ejemplar [cosa realizada por mí un largo año antes, 1992, de tropezar con esta nota: 16-XII-1993]. Yo lo pasé muy bien traduciéndolo porque el libro es una preciosidad. No puedo comprender cómo llegué a quedarme sin un ejemplar de mi traducción.

Estos días he traducido un ensayo de Stevenson y hay algo en él con lo que no estoy conforme. Es el ensayo, tan bonito y tan triste, que llama Ordered South [Al sur, en la traducción de nuestra escritora].

¿Como puede decir, el observador tan fino, lo que dice? No. El hombre joven no tiene, no puede tener la conciencia [adjetivo ininteligible] de su inutilidad en el mundo. El domingo, en un paseo mañanero, coincidí con una carrera de bicicletas. Todo el camino, antes de llegar los corredores, ya estaba lleno de público, que esperaba de [palabra dudosa] con cara [adjetivo ininteligible], como pedía la ocasión de la inminente fiesta, y de otros corredores, y aun corredoras, de menor cuantía pero ansiosos de poder probar, en el mismo circuito que los campeones, sus pulmones y sus piernas. Nada más tonto que una carrera de bicicletas. Pero alli estaban gozando plenamente con ella varios miles de personas, la mayor parte jovenes. Y si fuera posible ir preguntando uno por uno a todos si se sentian inútiles en el mundo y sufrian por ello, nos mirarian seguramente con ojos de asombro primero para soltar después una estentórea carcajada o dar media vuelta sin hacernos más caso, dejándonos por imposibles. ¡Inútiles! Ya lo creo que pueden serlo y lo serán muchos que ni pan ni consuelo ni alegría llevarán a sus casas, pero nunca llegó el pensamiento a insinuarse siquiera en sus cabezas, llenas de los kilómetros que hay que andar, de si engranaría la cadena suavemente, de si está cómodo el sillín y responden las fuerzas. Porque un joven no necesita más. Lo demás, el gozar con la mañana luminosa que les envuelve con la gloria de las copas doradas de los árboles, con la [palabra ininteligible] tranquila armonía de blanco y azul en el cielo son cosas que, si se les dan, se les darán por añadidura. Pero un joven, un cuerpo joven y un espíritu joven, no necesita nada de esto para justificarse. Les basta el perfecto funcionamiento, la elasticidad del resorte de su organismo. La sangre fluye con calor y todo lo justifica y lo borra todo. Lo borra todo. Amores, poesía, responsabilidad. Cuando un cuerpo joven, al salir del encierro forzado de unas horas, siente desperezarse sus miembros y las fibras más últimas de su bien templado organismo, y esto le hace saltar porque sí, no más que porque es joven, por encima de un banco, 
no le preguntemos por su justificación en la vida. Esa es su justificación. Un hombre joven y sano es un gran egoísta. Está tan lleno de sí que no le queda espacio ni tiempo ni ojos para nada. Stevenson reconoce este estar desligado, aun del amor [palabra ininteligible] de sus padres y es en eso en lo que funda la supuesta sensación de inutilidad. Al revés, al revés. Es su fundamental egoísmo lo que borra todo lo que no sea ellos; tienen en sí mismos y en su perfecto funcionamiento fisiológico su justificación. 